eCommons@AKU

May 1992

\title{
Randomised comparison of oral ofloxacin alone with combination of parenteral antibiotics in neutropenic febrile patients
}

\author{
IA. Malik \\ Z Abbas \\ Aga Khan University, zaigham.abbas@aku.edu \\ M Karim \\ Aga Khan University
}

Follow this and additional works at: https://ecommons.aku.edu/

pakistan_fhs_mc_med_gastroenterol

Part of the Gastroenterology Commons

\section{Recommended Citation}

Malik, I. A., Abbas, Z., Karim, M. (1992). Randomised comparison of oral ofloxacin alone with combination of parenteral antibiotics in neutropenic febrile patients. Lancet, 339(8801), 1092-1096.

Available at: https://ecommons.aku.edu/pakistan_fhs_mc_med_gastroenterol/223 


\title{
Randomised comparison of oral ofloxacin alone with combination of parenteral antibiotics in neutropenic febrile patients
}

\author{
ImTIAZ A. MALIK ZAIgham AbBas Michele Karim
}

Prompt treatment with empirical antibiotics in neutropenic febrile patients reduces morbidity and mortality. Most patients have been treated with parenteral combination antibiotics, but newer antibiotics with broad-spectrum bactericidal activity have made monotherapy feasible. Ofloxacin, a broad-spectrum fluoroquinolone, has the additional advantage that bactericidal concentrations can be achieved with oral administration. We have compared ofloxacin as an oral single agent with standard parenteral combination antibiotics for the management of neutropenic febrile patients in a prospective, randomised trial.

Patients with severe neutropenia (absolute neutrophil count $\leqslant 0.5 \times 10^{9} / \mathrm{l}$ ), fever above $38^{\circ} \mathrm{C}$, and ability to take drugs by mouth were eligible for the study. After initial investigations, 60 patients were randomly assigned to oral ofloxacin $400 \mathrm{mg}$ twice daily and 62 to parenteral combination antibiotic therapy (amikacin $15 \mathrm{mg} / \mathrm{kg}$ daily, plus, at various times in the trial, carbenicillin, cloxacillin, or piperacillin). Patients were examined $72 \mathrm{~h}$ and 7 days after the start of treatment and when neutropenia resolved. 24 (40\%) ofloxacin-treated and $26(42 \%)$ combination-treated patients had pyrexia of unknown origin (PUO). In both treatment groups, the treatment success rate was higher for such patients than for those with clinically or microbiologically documented infections (92\% vs $67 \%$ [p<0.05] for ofloxacin; $85 \%$ vs $64 \%$ for combination). There were no significant differences in success rates of ofloxacin and combination treatment for these subgroups or overall ( $77 \%$ vs $73 \%$ ). Patients with neutropenia for less than 1 week had better responses to both treatments than patients with longer-lasting neutropenia. There were $4(7 \%)$ deaths in the ofloxacin group and $6(10 \%)$ in the combination group. Both regimens were well tolerated.

We conclude that oral single-agent ofloxacin is as effective as parenteral combination antibiotic therapy in neutropenic febrile patients, especially those expected to have short durations of neutropenia.

Lancet 1992; 339: 1092-96.

\section{Introduction}

The prompt initiation of empirical broad-spectrum antibiotic treatment in neutropenic febrile patients significantly reduces morbidity and mortality. ${ }^{1,2}$ Owing to the limited antibacterial spectra of older antibiotics, which individually have an overall response rate of about $50 \%$, parenteral combination chemotherapy has been considered necessary to achieve the synergy and high bactericidal activity in serum that leads to a good outcome. ${ }^{3.5}$ Combination therapy also prevents the emergence of resistant organisms. ${ }^{6}$ Such treatment is, however, expensive and can be toxic, especially if aminoglycosides are part of the combination.

Some newer antibiotics have a broad spectrum and similar bactericidal activity to combination therapy $\mathrm{y}^{7.8}$ and have been used as single agents in the management of neutropenic febrile patients. The newer fluoroquinolones are potential agents for monotherapy. High bactericidal serum concentrations can be achieved even when they are given by mouth, ${ }^{9}$ which gives these drugs an enormous advantage over parenteral antibiotics for cancer patients with problems of venous access.

We have compared the quinolone ofloxacin given by mouth with parenteral combination antibiotic therapy in a randomised prospective study of neutropenic febrile patients. The study was designed for haemodynamically stable patients who were able to take drugs by mouth and were expected to have short durations of neutropenia.

\section{Patients and methods}

All patients treated by the oncology service during the 2 years 1989-91 entered the study if they had fever above $38^{\circ} \mathrm{C}$ measured orally at least twice $4 \mathrm{~h}$ apart in a day, or a single value of $38.5^{\circ} \mathrm{C}$ or higher unrelated to the administration of pyrogenic agents; and an absolute neutrophil count of $0.5 \times 10^{9} / 1$ or lower, or a count below $1.0 \times 10^{9} / 1$ as long as it fell below $0.5 \times 10^{9} / 1$ within $24 \mathrm{~h}$ of entry to the study. Reasons for exclusion were: known hypersensitivity to any of the antibiotics used or related products; antibiotic treatment within the preceding $96 \mathrm{~h}$; pregnancy; lactation; age under 16 years; renal insufficiency (serum creatinine $>221 \mu \mathrm{mol} / \mathrm{l}$ or need for dialysis); hepatic insufficiency (alanine aminotransferase activity more than 4 times normal); inability to take oral medications caused by painful mouth ulcers, intestinal malabsorption, or severe nausea and vomiting; recurrent pyrexia of undetermined origin (PUO); and shock (systolic blood pressure $<80 \mathrm{~mm} \mathrm{Hg}$ or peripheral circulatory failure).

After giving informed consent, each patient underwent a complete physical examination with history-taking, complete blood count, urine analysis, measurement of blood urea nitrogen, creatinine, and electrolytes, liver function tests, and chest radiography. Cultures of throat swabs, urine, and faeces, at least two blood cultures, and fine-needle aspiration and culture of any possible source of infection were done. The sensitivities of microbial isolates were assessed on Kirby-Bauer agar-diffusion plates. Patients were then randomly assigned one of the treatment regimens by means of consecutively drawn sealed envelopes. Patients assigned ofloxacin received $400 \mathrm{mg} / \mathrm{kg}$ daily. Patients assigned parenteral treatment received one of three combinations.

ADDRESSES: Department of Medicine, Aga Khan University Hospital, Karachi, Pakistan (I. A. Malik, MD, Z. Abbas, FCPS, M. Karim, $M D$ ) and Division of Hematology-Oncology, Department of Medicine, University of California Irvine Medical Center, California, USA (I. A. Malik). Correspondence to Dr Imtiaz A. Malik, Aga Khan University Hospital, Stadium Road, PO Box 3500, Karachı 74800, Pakistan. 
TABLE LCLINICAL CHARACTERISTICS OF STUDY PATIENTS

\begin{tabular}{l|c|c}
\hline \multicolumn{1}{|c|}{} & $\begin{array}{c}\text { Ofloxacin } \\
\text { group } \\
(\mathrm{n}=60)\end{array}$ & $\begin{array}{c}\text { Combination } \\
\text { group } \\
(\mathrm{n}=62)\end{array}$ \\
\hline Male/female & $29 / 31$ & $30 / 32$ \\
Mean (SD) age in yr & $37 \cdot 9(7 \cdot 3)$ & $34 \cdot 5(14 \cdot 6)$ \\
No (\%) with: & $32(53 \%)$ & $35(57 \%)$ \\
Leukaemia or lymphoma & $7(12 \%)$ & $8(13 \%)$ \\
Aplastic anaemia & $21(35 \%)$ & $19(31 \%)$ \\
Solid tumours & & \\
Mean neutrophil count on admission & $0 \cdot 15(0-0 \cdot 55)$ & $0 \cdot 16(0-0 \cdot 57)$ \\
(×10\%/I) & $32(53 \%)$ & $34(55 \%)$ \\
No (\%) with neutrophil count & $9 \cdot 1(5 \cdot 7)$ & $9 \cdot 4(5 \cdot 1)$ \\
$<0 \cdot 10 \times 10^{9} / I$ & $24(40 \%)$ & $26(42 \%)$ \\
Mean (SD) duration of neutropenia (days) & $36(60 \%)$ & $36(58 \%)$ \\
No (\%) with PUO & 14 & 18 \\
No (\%) with documented infection & 14 & 11 \\
Clinical & 8 & 7 \\
Microbiological without bacteraemia & & \\
Microbiological with bacteraemia & \\
\hline
\end{tabular}

We chose amikacin ( $15 \mathrm{mg} / \mathrm{kg}$ daily) because gentamicin resistance among gram-negative isolates at our hospital is common. ${ }^{10}$ Initially, we combined amikacin with carbenicillin ( $400 \mathrm{mg} / \mathrm{kg}$ daily) but the high cost of this drug in such doses and the high rate of carbenicillin resistance in pseudomonas isolate ${ }^{10}$ led us to discontinue its use. Owing to the prominence of gram-positive isolates, ${ }^{6}$ we changed to cloxacillin ( 1 g every $6 \mathrm{~h})$. We later changed to piperacillin ( $4 \mathrm{~g}$ every $4 \mathrm{~h}$ ) when this drug became available in our hospital, to provide better activity against gram-negative organisms and so that we were comparing ofloxacin with the best available combination.

Each febrile episode was classified as either due to a clinically or microbiologically documented infection or of undetermined origin (PUO). For a microbiologically documented infection, bacterial pathogens were isolated from blood, bone marrow, urine, pus, or exudates and there was clinical, laboratory, or radiographic evidence of infection at the same sites. Criteria for microbiologically documented infection were similar to those of Pizzo et al. ${ }^{11}$ In a clinical infection, there was clear clinical evidence of infection but no organism could be isolated. This category included cellulitis, culture-negative pneumonia, necrotising oral mucositis, and marginal gingivitis. PUO was defined as an episode for which there was no clinical or microbiological evidence of infection within $72 \mathrm{~h}$ of entry to the study.

Clinical and microbiological outcome were evaluated at $72-96 \mathrm{~h}$, 7 days after the start of antibiotic treatment, and at the resolution of neutropenia, so that we could assess the efficacy of treatment. ${ }^{12}$ Each patient was physically examined every day. Blood cultures and counts were done daily if fever persisted at $38^{\circ} \mathrm{C}$ or above. Liver function tests, clotting profile, and chest radiography were repeated weekly if fever persisted. Treatment outcomes were classified into three categories. ${ }^{12}$

Failure-Patients whose infections progressed within $72 \mathrm{~h}$, shown by the presence of worsening obvious source of infection, shock, or continuing positive blood cultures, were considered to have treatment failure and were withdrawn from the study. Persistence of fever alone was considered a treatment failure if there was no change after 4 days of antibiotic therapy, unless an identified site of infection had shown substantial improvement. This category also included patients who initially responded to treatment but ultimately did not recover from fever and neutropenia and died.

Success without modification - These patients recovered from fever and neutropenia without any modification of the initial regimen.

Success with modification-included eposides in which the patient recovered from the fever and neutropenia but required additional treatment with an antibiotic against gram-positive or gram-negative organisms as well as empirical antifungal treatment with amphotericin or antiviral therapy with acyclovir. However, crossover from one arm to the other was not permitted.

Nephrotoxicity was defined as a rise of $44 \mu \mathrm{mol} / 1$ in serum creatinine from the previous measurement. Hepatotoxicity was defined as a doubling of pretreatment activities of aminotransferases or alkaline phosphatase. Other toxic effects (eg, drug-related rashes)
TABLE II-BACTERIAL ISOLATES FROM PATIENTS WITH PROVEN INFECTIONS

\begin{tabular}{|c|c|c|}
\hline - & $\begin{array}{l}\text { Ofloxacin } \\
\text { group }\end{array}$ & $\begin{array}{c}\text { Combination } \\
\text { group }\end{array}$ \\
\hline \multicolumn{3}{|l|}{ Urine } \\
\hline Enterobacter $\mathrm{sp}$ & 2 & 0 \\
\hline Escherichia coli & 2 & 1 \\
\hline Enterococcus D & 0 & 2 \\
\hline Citrobacter $\mathrm{sp}$ & 0 & 2 \\
\hline Acinetobacter sp & 1 & 0 \\
\hline \multicolumn{3}{|l|}{ Wounds and pustules } \\
\hline Staphylococcus aureus & 3 & 4 \\
\hline Pseudomonas sp & 1 & 3 \\
\hline Acinetobacter sp & 2 & 0 \\
\hline$\beta$-haemolytic streptococci & 3 & 0 \\
\hline \multicolumn{3}{|l|}{ Sputum } \\
\hline Pseudomonas sp & 2 & 4 \\
\hline$S$ aureus & 2 & 3 \\
\hline Klebsiella sp & 1 & 4 \\
\hline Candida sp & 2 & 3 \\
\hline \multicolumn{3}{|l|}{ Throat swab } \\
\hline$\beta$-haemolytic streptococci & 1 & 0 \\
\hline Candida albicans & 2 & 0 \\
\hline \multicolumn{3}{|l|}{ CVP catheter } \\
\hline Pseudomonas sp & 1 & 1 \\
\hline Candida $\mathrm{sp}$ & 0 & 1 \\
\hline \multicolumn{3}{|l|}{ Ascitic tap } \\
\hline$E$ coli & 0 & 1 \\
\hline \multicolumn{3}{|l|}{ Blood } \\
\hline$S$ aureus & 2 & $2(1)$ \\
\hline Pseudomonas sp & $2(1)$ & $2(1)$ \\
\hline Salmonella sp & 1 & 0 \\
\hline Klebsiella sp & 0 & 1 \\
\hline Ecoli & 0 & 1 \\
\hline Streptococcus viridans & $1(1)$ & 0 \\
\hline Coryneforms & 0 & $0(1)$ \\
\hline Bacillus sp & 1 & $0(1)$ \\
\hline Candida tropicalis & 0 & $0(1)$ \\
\hline
\end{tabular}

*Two isolates were obtaned for 4 patients Numbers represent initial isolates with breakthrough isolates in parentheses.

were individually determined. Amikacin concentrations were not routinely measured. Antibiotic dose was adjusted for renal impairment.

The Epi Info statistical package was used for the preliminary analysis. Initially all 137 subjects (68 ofloxacin, 69 combination) were included in an analysis of clinical characteristics. 15 randomised patients ( 8 ofloxacin, 7 combination) were excluded because the neutrophil count did not fall below $0.5 \times 10^{9} / 1$ within $24 \mathrm{~h}$ (in 10 patients), the patient had received antibiotics within the previous $96 \mathrm{~h}$ (3), a rash developed (1 ofloxacin-treated patient), or because the patient was in shock at entry (1). These 15 patients did not differ significantly from the 122 evaluable patients in any clinical characteristic apart from mean neutrophil count and duration of

TABLE III-RESPONSE RATES AND SURVIVAL DATA

\begin{tabular}{|c|c|c|c|c|}
\hline \multirow[b]{2}{*}{ - } & \multicolumn{2}{|c|}{ Ofloxacin } & \multicolumn{2}{|c|}{ Combination } \\
\hline & $\begin{array}{c}\text { PUO } \\
(n=24)\end{array}$ & $\begin{array}{c}\text { Documented } \\
\text { infection } \\
(n=36)\end{array}$ & $\begin{array}{c}P \cup O \\
(n=26)\end{array}$ & $\begin{array}{l}\text { Documented } \\
\text { infection } \\
(n=36)\end{array}$ \\
\hline $\begin{array}{l}\text { Success without } \\
\text { modification }\end{array}$ & 18 & 14 & 18 & 15 \\
\hline Success with modification & 4 & 10 & 4 & 8 \\
\hline Failure & 2 & 12 & 4 & 13 \\
\hline Success rate & $92 \%$ * & $67 \%$ & $85 \%$ & $64 \%$ \\
\hline $\begin{array}{l}\text { Duration of fever (days) in } \\
\text { successfully treated } \\
\text { episodes }\end{array}$ & $4 \cdot 0$ & $4-4$ & $4 \cdot 3$ & $4 \cdot 3$ \\
\hline $\begin{array}{l}\text { Deaths due to treatment } \\
\text { failure }\end{array}$ & 1 & 3 & 2 & 4 \\
\hline Overall success & \multicolumn{2}{|c|}{$77 \%$} & \multicolumn{2}{|c|}{$73 \%$} \\
\hline Failure rate & \multicolumn{2}{|c|}{$23 \%$} & \multicolumn{2}{|c|}{$27 \%$} \\
\hline $\begin{array}{l}\text { No }(\%) \text { deaths in each } \\
\text { arm } \\
\text { Deaths as } \% \text { of failure }\end{array}$ & \multicolumn{2}{|c|}{$\begin{array}{l}4(7 \%) \\
29 \%\end{array}$} & \multicolumn{2}{|c|}{$\begin{array}{l}6(10 \%) \\
35 \%\end{array}$} \\
\hline
\end{tabular}

*Sıgnıficantly hıgher than ofloxacin for documented infections $(p<005)$ 


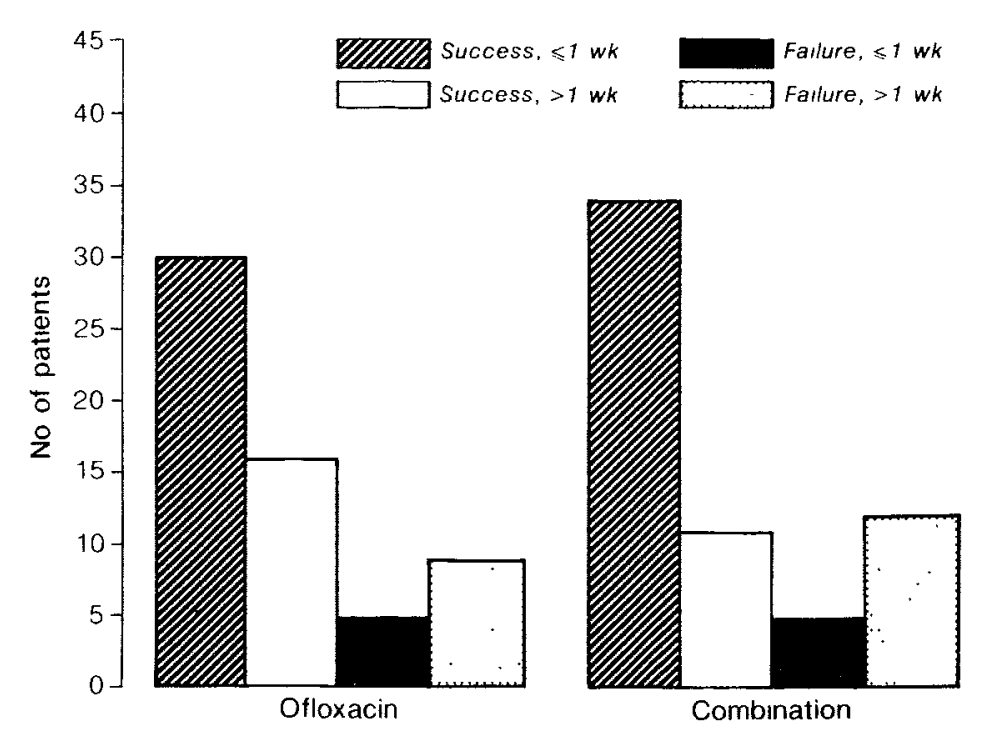

Fig 1-Effect of duration on clinical response.

neutropenia (the main reason for patient exclusion was lack of expected fall in the neutrophil count). More of the excluded patients had PUO than had documented infections. However, exclusion of these patients had no significant effect on any study variable. Subsequent reanalysis was done for 122 patients. The three combination groups were analysed separately but did not differ significantly in response rate so for all purposes were analysed collectively as the combination arm.

Response rates in the two groups were compared by Fisher's exact test (causes of fever and response rate in relation to type of success) or the chi-square test (all other comparisons). Duration of fever was used to calculate Kaplan-Meier survival curves and differences between the curves were estimated by log-rank analysis.

\section{Results}

No episode of renal or hepatic toxicity occurred during the study in any of the 137 patients initially entered. 15 randomised patients were excluded (see methods); of the remaining 122 patients, 60 were treated with ofloxacin and 62 with parenteral combination therapy (10 amikacin + carbenicillin, 41 amikacin + cloxacillin, 11 amikacin + piperacillin). The ofloxacin and combination groups were well matched for age, sex, underlying neoplasm, mean neutrophil count, and duration of neutropenia (table I).

At the initial evaluation (at $72 \mathrm{~h}$ ) 50 patients had PUO, 32 had clinically documented infection, 25 microbiologically documented infection without bacteraemia, and $15(12 \%)$ documented bacteraemia (table I). The most striking feature

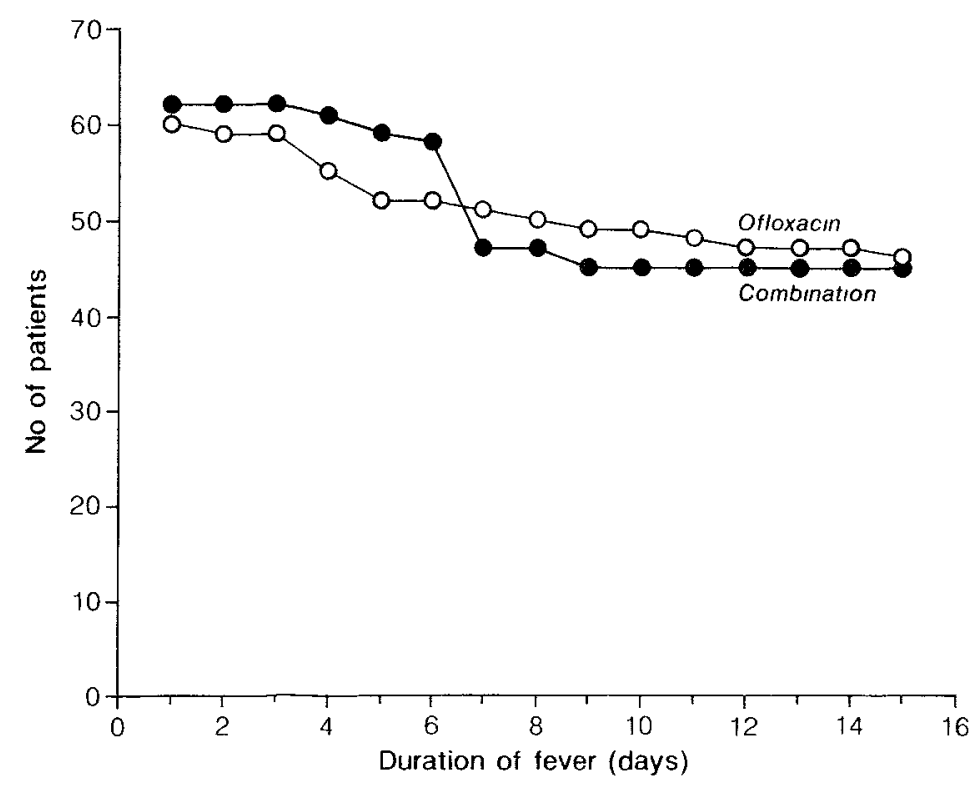

Fig 2-Time to treatment failure. of the organisms isolated (table II) is the frequency of gram-positive isolates from blood cultures.

There were no significant differences between the ofloxacin and combination groups in clinical success rate, though within each treatment group the success rate was higher for patients with PUO than for those with clinically or microbiologically documented infections; the difference reached significance in the ofloxacin group $(p<0.05$; table III). Bacteraemia recurred in 5 patients in the combination group and 2 in the ofloxacin group. These cases were considered treatment failures. The average duration of fever was similar in both groups. The difference in death rate between the combination and ofloxacin groups was not significant, though our sample size may be too small to detect a difference. 1 ofloxacin-treated patient died on day 4 and 1 patient receiving the antibiotic combination died on day 6 . All 8 other deaths occurred after 2 weeks in patients who were receiving multiple antibiotics and antifungal treatment. The duration of neutropenia contributed substantially to the success rate in both groups. Among both ofloxacin-treated and combination-treated patients, those who had neutropenia for less than a week had significantly higher success rates than those with longer-lasting neutropenia ( $\mathrm{p}<0.05$ and $<0.001$, respectively; fig 1 ). There was no significant difference between the groups in time to treatment failure (fig 2).

\section{Discussion}

Despite substantial improvements in the supportive care of patients with malignant disorders, the clinical course of patients with neutropenia continues to be complicated by fever and infection. ${ }^{13} 60 \%$ of such febrile episodes are due to microbiologically or clinically documented infection. ${ }^{14}$ The pathogens that cause the initial infections are few (table II). Although gram-positive organisms are being isolated with increasing frequency, gram-negative pathogens contribute $50 \%$ of isolates in most studies and account for early morbidity and mortality. ${ }^{15}$ The standard approach to treatment has been to use a parenteral antibiotic combination, especially for the management of the more virulent gram-negative infections. ${ }^{5-7}$ However, the potential toxic effects on kidney and ears of aminoglycosides, the risk of antibiotic antagonism with double beta-lactam combinations, ${ }^{16}$ and the high cost are drawbacks; monotherapy has become feasible with the availability of broad-spectrum bactericidal agents.

There have been several comparative trials of a broadspectrum single agent $v s$ antibiotic combinations. ${ }^{2,17-24}$ The fluoroquinolones are well tolerated, with fewer adverse effects than more commonly used agents, they are bactericidal against most species of bacteria, and their oral bioavailability exceeds $50 \% .{ }^{9}$ These features make the fluoroquinolones almost ideal agents for monotherapy in neutropenic febrile patients. Ease of administration of ofloxacin by mouth to patients with compromised venous access and the cost-effectiveness of monotherapy prompted our comparative trial.

Our two study groups were similar as regards demographic and clinical characteristics; most importantly, similar proportions had PUO, and the rate of PUO was lower than in a previous study ${ }^{11}$ of ceftazidime $v$ s combination therapy in which the proportions with PUO were $67 \%$ vs $76 \%$, respectively. The high percentage of patients in our study who had documented clinical or microbiological infection makes the efficacy of ofloxacin more impressive. Exclusion of patients in shock and those 
unable to take drugs by mouth could have biased the results in favour of ofloxacin. We were unsure how well ofloxacin would be absorbed in a patient with haemodynamic compromise, so we excluded all patients in shock. Until the use of ofloxacin in shock is tested in a controlled trial, we do not recommend such use. Antibiotic concentrations were not routinely measured in our study patients. Although such measurements confirm the adequacy of the antibotic dose, our overall success rate is similar to rates when aminoglycoside concentrations were closely monitored. ${ }^{11}$

Our study may be criticised for the changes made in the combination antibiotics group. The study was designed to compare oral single agent with parenteral combination antibiotics. The changes in combination therapy could not have affected patient selection, but they could have altered the efficacy of combination treatment. Comparison of the overall success rate with each of the three combinations showed no significant differences. Since the overall success rate and mortality of our combination group are similar to or better than those reported by others, we believe that changes in the combination treatment did not adversely affect the results.

Ciprofloxacin has equal efficacy in combination with aminoglycosides or with beta-lactam antibiotics. ${ }^{22,25,26}$ However, one study suggested that it was less effective in gram-positive than in gram-negative bacteraemias. The limited efficacy against streptococci can lead to superinfection in neutropenic patients receiving ciprofloxacin as sole therapy. ${ }^{23}$ In our study, only 1 patient had breakthrough bacteraemia with Streptococcus viridans in the ofloxacin group. Although this episode was classified as a treatment failure, it did not cause death. However, 3 of 5 patients with breakthrough bacteraemia in the combination group died.

Wide variations of study design and endpoints can lead to conflicting results. ${ }^{27}$ Pizzo et al ${ }^{11}$ suggest ultimate patient survival as the endpoint, whereas others emphasise the importance of treatment of infection and development of subsequent infections. The criteria for failure in our study, similar to those of EORTC, ${ }^{28}$ meant that the death rate was much lower than the failure rate. In addition, crossover was not permitted. With death as the only criterion of failure, ${ }^{11}$ our overall success rates were even higher $(93 \%$ with ofloxacin and $90 \%$ with combination antibiotics). In our study, as in the EORTC study, ${ }^{28}$ there was a significant difference in outcome for PUO and for documented infections in the monotherapy group; ${ }^{28}$ there was also a difference between these two categories with combination treatment, though it was not significant.

A significantly lower response rate has been reported for patients who have profound neutropenia for a long time than for patients with less severe or long-lasting neutropenia. ${ }^{3,4}$ The number of circulating granulocytes is the single most important factor in determining efficacy of an antibiotic regimen. ${ }^{5}$ In both our treatment groups, response rates were lower in the patients with neutropenia for longer than a week.

A possible disadvantage of monotherapy is the greater potential for development of resistance during treatment than with a combination. Emergence of resistance has been reported with the broad-spectrum penicillins, ${ }^{24,29}$ but Pizzo et al did not observe resistance during 5 years of ceftazidime use. ${ }^{11}$ Resistance to ciprofloxacin despite concomitant treatment with other antibiotics was reported in one study but not in others. ${ }^{22,26,30}$ An outbreak of ciprofloxacinresistant Staphylococcus epidermidis was reported by Chan et al. ${ }^{25}$ During 2 years' use of ofloxacin, we did not see any cases of resistance.
Our most important finding is that a single agent taken by mouth was as effective as combination antibiotic therapy in neutropenic febrile patients. Oral ofloxacin is cheap, welltolerated, non-toxic, and the most cost-effective way to manage patients with fever and neutropenia. In Pakistan, the combination therapy is thirteen times more expensive than ofloxacin alone. In developing countries, cost is an important factor that influences compliance and ultimate care. Ofloxacin seems to be especially suitable for patients who are expected to have short durations of neutropenia. Use of ofloxacin might allow early discharge from hospital of a patient who becomes afebrile but continues to be neutropenic. It could even enable effective outpatient management of such neutropenic febrile patients. A trial of outpatient use of ofloxacin is underway.

We thank Dr T. C. Cesario, University of California, Irvine, and Dr P. A Pizzo, National Cancer Institute, Bethesda, Maryland, for critical review of the manuscript and helpful suggestions; Dr Farid Midhat, Aga Khan University Hospital, for the statistical analysis; the attending staff and house-staff of the Aga Khan University Hospital, who took part in the study; and $\mathrm{Mr}$ Sulaiman Sadruddin for preparing the paper.

\section{REFERENCES}

1. Rubin RH. Empiric antibacterial therapy in granulocytopenia induced by cancer chemotherapy. Ann Intern Med 1988; 108: 134-36.

2. Hathorn JW, Rubin M, Pizzo PA. Empirical antibiotic therapy in the febrile neutropenic cancer patient: clinical efficacy and impact of monotherapy. Antimicrob Agents Chemother 1987; 31: 971-77.

3. Klastersky J, Cappel R, Daneau D. Clinical significance of in vitro synergism between antibiotics in gram-negative infections. Antimicrob Agents Chemother 1972; 2: 470-75.

4. Anderson ET, Young LS, Hewitt WL. Antimicrobial synergism in the therapy of gram-negative rod bacteremia. Chemotherapy 1978; 24: 45-54.

5. De Jongh CA, Joshi JH, Newman KA, et al. Antibiotic synergism and response in gram negative bacteremia in granulocytopenic cancer patients. Am $\mathcal{F}$ Med 1986; 80 (suppl SC): 36-100.

6. Wade JC, Schimpff SC. Approaches to therapy for bacterial infections in the granulocytopenic patient. In: Klastersky J, ed. Infections in cancer patients. New York: Raven, 1982: 105-29.

7. Wade JC, Johnson DE, Bustamante CI. Monotherapy for empiric treatment of fever in granulocytopenic cancer patients. Am $\mathcal{Y}$ Med 1986; 80: (suppl 5C): 85-95.

8. Van Laethem Y, Lagast YH, Klastersky J. Serum bactericidal activity of ceftazidime and cefoperazone alone or in combination with amikacin against Pseudomonas aeruginosa and Klebstella pneumoniae. Antimicrob Agents Chemother 1983; 23: 435-39.

9. Sanders CC. Ciprofloxacin in vitro activity, mechanism of action and resistance. Rev Infect Dis 1988; 10: 516-26.

10. Karim M, Khan W, Farooq1 B, Malik I. Bacterial isolates in neutropenic febrile patients. F Pakistan Med Assoc 1991; 41: 35-37.

11. Pizzo PA, Hathorn JW, Hiemenz JW, et al. A randomized trial comparing ceftazidime alone with combination antibiotic therapy in cancer patients with fever and neutropenia. $N$ Engl f Med 1986; 315: 552-58.

12. Pater JL, Weir L. Reporting the results of randomized trials of empiric antibiotics in febrile neutropenic patients: a critical survey. 7 Clin Oncol 1986; 4: 346-52.

13. Bodey GP, Buckley M, Sathe YS, Freireich EJ. Quantitative relationships between circulating leukocytes and infection in patients with acute leukemia. Ann Intern Med 1966; 64: 328-40.

14. EORTC International Antimicrobial Therapy Project Group. Three antibiotic regimens in the treatment of infection in granulocytopenic patients with cancer. F Infect Dis 1978; 137: 14-29.

15. Wade JC, Schimpff SC, Newman KA, Wiernick PH. Staphylococcus epidermidis: an increasing cause of infection in patients with granulocytopenia. Ann Intern Med 1982; 97: 503-08.

16. Sander CC, Sander WE Jr, Goerng RV. In vitro antagonism of beta-lactam antibiotics by cefoxitin. Antimicrob Agents Chemother 1982; 21: 968

17. Piccart $M$, Klastersky J, Meunier F, Lagast $H$, Van Laethem $Y$, Weerts D. Single agent versus combination empirical therapy for gram negative bacillary infections in febrile cancer patients with and without granulocytopenia. Antimicrob Agents Chemother 1984; 26: 870-75.

18. Wade JC, Standiford HC, Drusano GL, et al. Potential of imipenum as single agent empiric antibiotic therapy of febrile neutropenic patients with cancer. Am 7 Med 1985; 78 (suppl 6A): 62-72. 
19. Morgan G, Duerden DI, Lilleyman JS. Ceftazidime as a single agent in the management of children with fever and neutropenia. $\mathcal{F}$ Antimicrob Chemother 1983; 12 (suppl A): 347-51.

20. Fainstein V, Bodey GP, Elting L, et al. A randomized study of ceftazidime compared to ceftazidime and tobramycin for the treatment of infections in cancer patients. F Antimicrob Chemother 1983; 12 (suppl A): 101-10.

21. Reilly JT, Brada M, Bellingham AJ, Hart CA, Bennet C. Cefatizidime compared to tobramycin and ticarcillin in immunocompromised hematological patients. f Antimicrob Chemother 1983; 12 (suppl A): 89-92.

22. Kelsey SM, Wood ME, Shaw E, Newland AC. Intravenous ciprofloxacin as empirical treatment of febrile neutropenic patients. $\mathrm{Am}$ $\mathcal{F}$ Med 1989; 87 (suppl 5A): 274S-77S.

23. Bayston K, Want $S$, Cohen J. Monotherapy in the febrile neutropenic patient: a prospective randomized trial of ciprofloxacin versus ceftazidime. In: Proceedings of the 5th International Symposium on Infection in the Immunocompromised Host. June, 1988: Noord Wijkerhout, Holland: 7.

24. Issell BF, Bodey GP. Mezlocillin for treatment of infections in cancer patients. Antimicrob Agents Chemother 1980; 17: 1008-18.
25. Chan CC, Oppenheim BA, Anderson H, Swindell R, Scarffe JH. Randomized trial comparing ciprofloxacin plus netilmicin versus piperacillin plus netilmicin for empiric treatment of fever of neutropenic patients. Antimicrob Agents Chemother 1989; 33: 87-91.

26. Flaherty JP, Waitley D, Edlin B, et al. Multicenter randomized trial of ciprofloxacin plus azlocillin versus ceftazidime plus amikacin for empiric treatment of febrile neutropenic patients. Am f Med 1989;87 (suppl 5A): 278S $82 \mathrm{~S}$.

27. Elliot CR, Pater JL. The effect of different measures of outcome on the results of studies of empiric antibiotic therapy in febrile neutropenic patients. Clin Invest Med 1988; 11: 327-30.

28. EORTC International Antimicrobial Therapy Project Group. Three antibiotic regimens in the treatment of infection in granulocytopenic patients with cancer. $\mathcal{F}$ Infect Dis 1978; 137: 14-29.

29. Wade JC, Schimpff SC, Newman KA, Fortner CL, Standiford HC, Wiernik PH. Piperacillin or ticarcillin plus amikacin: a double-blind prospective comparison of empiric antibiotic therapy for febrile granulocytopenic cancer patients. Am f Med 1981; 71: 983-90.

30. Kibbler CC, Pomeroy L, Sage R, Mannan P, Noone P, Prentice HG. The use of ciprofloxacin in the treatment of febrile neutropenic patients (abstr 357). In: Proceedings of the Third European Congress of Clinical Microbiology. The Hague, Netherlands, 11-14 May, 1987.

\title{
Salmonella-triggered reactive arthritis
}

\author{
OUTI MÄKI-IKOLA KAISA GRANFORS
}

\section{Introduction}

Salmonella infections are becoming more common around the world. $^{1}$ Sometimes the consequences of salmonella infection may be more serious than a brief episode of gastroenteritis, since reactive arthritis $(\operatorname{ReA})$ may follow infection..$^{2-5}$ The incidence of ReA after salmonella infection has been reported to be between 1.2 and $7 \cdot 3 \%,{ }^{2}$ and an increase in the number of salmonella ReA cases has been noted. ${ }^{3}$ Clinical manifestations of ReA vary from slight arthralgia to severe disabling disease. ReA often appears one to three weeks after the onset of gastrointestinal infection and presents as a migratory, asymmetrical polyarthropathy. The pathogenesis of $\operatorname{ReA}$ remains unknown. We now review the latest findings with regard to salmonellatriggered ReA.

\section{Aetiology}

Of the 2000 different salmonella serotypes, 22 have been reported to trigger $\operatorname{ReA}^{2}$ About $60 \%$ of $\operatorname{ReA}$ cases are triggered by Salmonella typhimurium and $25 \%$ by $S$ enteritidis, and over $90 \%$ of cases are triggered by salmonellae that have $\mathrm{O}$-antigens in common with these two species (serotypes $\mathrm{B}$ and $\mathrm{D}$ ). We have described ReA after infections with $S$ montevideo, $S$ agona, $S$ saint paul, and $S$ java, species not previously reported to induce ReA. ${ }^{4,5}$ It has also been reported that the organisms need not be viable, since $\operatorname{ReA}$ has been observed after vaccination with heat-killed whole $S$ typhi in two patients. ${ }^{6}$

\section{Diagnosis}

Diagnosis is based on both clinical findings and laboratory evidence of salmonella infection. A definite diagnosis of salmonella infection can be made only by isolation of organisms from the patient. However, by the time arthritic complications appear, the patient has usually recovered from gastroenteritis and salmonella may no longer be detectable in faeces. Consequently, laboratory diagnosis of salmonella-triggered ReA often depends on detection of specific antibodies. ${ }^{2}$ The Widal agglutination test, first described in 1896, is the earliest and still most widely used serological test for salmonella infections; however, its value has been questioned. ${ }^{2}$ Tests for specific salmonella serotypes are laborious because of the large variety of serotypes and antigens. We have overcome this difficulty with an enzyme immunoassay (EIA) that detects antibodies to the lipopolysaccharides (LPSs) of $S$ typhimurium and $S$ enteritidis. ${ }^{7}$ At least $70 \%$ of the salmonellae isolated from humans, and more than $90 \%$ of those causing ReA, have $O$ side chains on their LPS that are identical to those of $S$ typhimurium and $S$ enteritidis. ${ }^{2}$ Moreover, the structure of the lipid A core of LPS is conserved among different species of salmonella, thus broadening the test's applicability. The EIA is more sensitive than the Widal test, and its value in clinical diagnosis of salmonella-triggered $\operatorname{ReA}$ has been demonstrated. , $, 5,8-10^{-10}$

In addition to serological tests, salmonella infections can be diagnosed by detecting salmonella antigens in joints or peripheral blood cells by immunofluorescence or immunoblotting, ${ }^{9}$ or by measuring the proliferative responses of synovial fluid or peripheral blood mononuclear cells to salmonella organisms. ${ }^{11}$ However, these tests are too laborious for routine diagnosis.

\section{Pathogenesis}

Several theories have been advanced to explain how inflammation in joints may be stimulated by microbial antigens originating from a remote site in the body. All these

ADDRESSES: National Public Health Institute, 20520 Turku, Finland (O. Mäki-lkola, MD, K. Granfors, PhD), and Department of Medical Microbiology. Turku University, Turku (K. Granfors) Correspondence to Dr Kaisa Granfors. 